\title{
ENGLISH LANGUAGE PROFICIENCY PROFILE: A CASE STUDY OF THE COMMUNICATION SKILLS OF DEAF STUDENTS IN THE UNDERGRADUATE PROGRAM IN QUEZON, PHILIPPINES
}

\author{
Mary Rose Q. Cabreros, MDC \\ Dalubhasaan ng Lungsod ng Lucena, Lucena City, Philippines \\ mqcabreros16@gmail.com
}

\begin{abstract}
Language acquisition may come naturally for people without sensorial disabilities. But for deaf children, language acquisition happens differently and comparably delayed than hearing children. This case study made an in-depth inquiry of the communication skills of the Special Education (SPED) students in one of the community colleges in Quezon Province, Philippines. An English Proficiency Test in the areas of Vocabulary, Grammar, Reading Comprehension, Analysis (Cause and Effect; Making Inferences) and Following Directions was given to the students. A Focus Group Discussion (FGD) was also conducted to gather data regarding problems encountered in their English classes. The gathered data were tabulated using frequency and percentage for the English Proficiency Test, while Conversation Analysis for FGD. The English Proficiency results revealed that Vocabulary, Reading Comprehension and Making Inferences were the three key areas where the respondents exhibit the lowest skills. These facts point out that teaching methods need to be adjusted to suit the needs of the SPED learners because the deaf's language formation is different in nature with that of the hearing. Thus, the researcher strongly recommends crafting a separate curriculum for the SPED students of the college.
\end{abstract}

Keywords: special education, language proficiency, sign language, $\mathrm{D} / \mathrm{HH}$ 


\section{Introduction}

Language is a central element to learning, as one cannot communicate understanding of a certain subject if there is no comprehension of language in any form. Language acquisition may come naturally for people without sensorial disabilities. But for deaf children language acquisition happens differently and comparably delayed than hearing children. Results in a study conducted by Campbell et. al. (2007) have indicated that the deaf use the same brain regions to process sign language as the hearing do when exposed to spoken English. The delays in language acquisition in deaf children translate prominently in their communication skills and thus have a distinct effect in their learning. Because of their language delays deaf learners also exhibit delays in their social cognition skills which are integral in how a student copes in his academic environment. In reading for instance, skills in social cognition allow a child to understand the perspective of different characters (Schick, 2014).

Language delays evident in deaf learners are attributed to the equally apparent poor academic performance of majority of them. Similar to hearing children a deaf child's first exposure to language is important in his development. It is unfortunate however, that vocabulary development for deaf children is extremely delayed. Learning in a mainstream set up may add to the pressure to come up with the language proficiency levels of their hearing peers in class.

The same holds true for the 23 deaf learners enrolled in the Associate in Computer Technology program under the BS in Information Technology department in one of the community colleges in the Quezon Province in the Philippines. Coping with the day to day tasks of fitting into the academic environment of a mainstream class is already a challenge. Let alone, passing their subjects particularly in English. Deaf learners in the BSIT-Special Education (SPED) program of the college attend all their classes mainstreamed with the hearing. The instructors handling the classes are all hearing, with the exception of only two instructors (also hearing) who serve as interpreters for all their classes. These interpreters are the only support service provided by the college for the deaf learners. One interpreter is assigned for one group who accompany them in all classes throughout the day to assist in all the lectures. 
INTERNATIONAL JOURNAL OF EDUCATIONAL MANAGEMENT AND

DEVELOPMENT STUDIES

Volume 1, Issue $1 \cdot$ September 2020 • ISSN 2719-0633 (PRINT) 2719-0641 (ONLINE)

These deaf learners barely pass their English subjects. And even if they do pass, it is mostly out of humanitarian reasons extended by the instructor. Their language delays attributed by their hearing impairment, and most probably the lack of proper support services for deaf learners may contribute to their difficulty in passing their classes, particularly their English subjects. To be able to provide the proper support services or device measures to augment the special needs of deaf learners, one must first study and understand their unique needs, by identifying first how they developed their acquisition of the English language as well as their English language proficiency.

This study assessed the English proficiency profile of the SPED students. On a general standpoint, the study profiled the proficiency levels of the SPED students. In addition, the unique needs of these deaf learners and learning differences with hearing students were assessed through a focused discussion on the problems in learning English in their English classes. As an offshoot of this case study, the researcher hopes to come up with appropriate measures to enhance the language learning of deaf students as well as suggest possible support services that may augment the gaps in their academic performance particularly in their English classes.

\section{Literature Review}

No other theory perhaps has the most ramification in how D/HH children acquire their language skills than Theory of the Mind (ToM). Piaget (1965) hinged of a similar view to that of ToM. However, the rudiments of taking into account the science of the mind began during the time of Descartes Second Mediation, where ToM's philosophical roots was first discussed. Theory of the Mind is "an important social cognitive skill" (Cherry \& Gan, 2020) that entails the ability to equate mental states - that of their own and of others. These mental states include beliefs, intents, desires, pretending, knowledge, etc. In other words, it is understanding how and why people feel and behave in a certain way, or having an integrated set of concepts underlying the understanding of the mind. At around the ages of 4-5, ToM normally develops for hearing children. However, for D/HH studies indicated that the language delays they experience also cause delayed understanding of ToM. 
INTERNATIONAL JOURNAL OF EDUCATIONAL MANAGEMENT AND

DEVELOPMENT STUDIES

Volume 1, Issue $1 \cdot$ September 2020 • ISSN 2719-0633 (PRINT) 2719-0641 (ONLINE)

A considerable number of studies postulate that $\mathrm{D} / \mathrm{HH}$ children delays in ToM are directly related to their language delays. Schick (2014) revealed in their study that the delays in the ToM skills of $\mathrm{D} / \mathrm{HH}$ children also translate to their skills involving verbal tasks and even those that require minimal language. Similar findings on the weakness of ToM among the deaf were revealed in the study of Fox and Falk (2019). Further, research in the last two decades pointed out that it is language deprivation and not auditory absence that cause ToM delays among the $\mathrm{D} / \mathrm{HH}$ children. Parental participation in the language development is then considered a decisive factor in how well the child develops language skills. The same effect is evident in language acquisition whether the child is born from deaf or hearing parents. Likewise, there is noteworthy evidence that deafness has long-term effects in language acquisition, which is a fact both for spoken or signed language.

Another theory that explains the language acquisition is the Nativist theory popularized by Noam Chomsky (1965). This theory posits that in language acquisition, humans have a set of rules embedded in their heads from birth. It simply means that humans acquire language skills not entirely through learned experiences, but also through an innate knowledge, already present within their systems. The same argument was pointed out by Pinker (1994) when he said that human language is a biological -adaptation language hardwired into one's mind by evolution. However, Hall, Hall \& Caselli (2019) posited the Language Scaffolding Hypothesis which states that language deprivation can compromise the proficiency in a child's language capabilities that in turn cause delays in their cognitive and socio-emotional development. Therefore, a $\mathrm{D} / \mathrm{HH}$ child needs to acquire mastery of any spoken or signed language to reach optimal development.

Parental factors and the choice of language used by the family of a D/HH child also figures prominently in their language acquisition. In a study conducted by Csizer and Kontra (2020) throughout the world there are approximately $90-95 \%$ of D/HH children that are born to hering parents. In addition, Marschark et al. (2015) found in a study that D/HH children born from parents who continually communicate to them from an early age are those who perform best in school. According to Easterbrooks \& Stoner (2006), however, many of them face difficulty in thought-formation in spoken language both at home and in school. Due to this, D/HH children fall behind in academic areas such as reading, spelling and writing 
INTERNATIONAL JOURNAL OF EDUCATIONAL MANAGEMENT AND

DEVELOPMENT STUDIES

Volume 1, Issue 1 · September 2020 • ISSN 2719-0633 (PRINT) 2719-0641 (ONLINE)

(Turnbull et. al., 2009). The three general areas where D/HH children encounter reading problems in particular, are in vocabulary, syntactic and figurative language. This goes the same for spoken language rules where the $\mathrm{D} / \mathrm{HH}$ have compromised access compared to children with normal hearing. Heward (2012) states that undoubtedly, this is a multifarious phenomenon that distresses a person's academic performance. For this same reason, Rowh (2006) postulates that deafness affects a person's communicative abilities and in turn adversely affects the potential academic and vocational success of an individual.

Deafness also affects literary behavior. Due to the distinctive language situation of deaf children their literacy behaviors, particularly their book orientation is affected. This is according to a study conducted in the Philippines by Bustos in 2007. Because of the absence of audition, these deaf children are devoid of phonemic cognizance, despite being able to identify and match letters. Thus they are more picture-governed than print-governed. Same conclusions were derived in a study conducted by Obosu, Opoku-Asare \& Deku (2016) in Ghana where subjects where subjects delivered in English language had serious impact on a D/HH child's academic success.

It is apparent that language delays experienced by $\mathrm{D} / \mathrm{HH}$ students directly affects their language proficiency and ultimately their academic performance. Deaf children are not just having difficulty with linguistic delays, according to Howerton-Fox \& Falk (2019), their perception and language development are likewise affected due to language deprivation. And this effect may possibly be permanent. Student's literacy development may be an equally difficult process especially for students with intricate linguistic histories. On the other hand, $\mathrm{D} / \mathrm{HH}$ students exhibit strong proficiencies in literacy areas at par with hearing peers, particularly in written expression discourse and phonological cognizance (Bowers et. al/, 2018). Scott \& Dostal (2019) added that at the macro-level deaf children exhibited at par performance with their hearing peers, but poorer in micro-level narrative skills, and when it comes to the implicative questions they showed less relevant and detailed answers when compared to their hearing peers.

As in any learning environment there are factors that dictate the efficacy and success of the teaching-learning process. In language learning, whether for hearing or D/HH students certain factors such as instruction, curriculum, teacher standards, materials, facilities, support 
INTERNATIONAL JOURNAL OF EDUCATIONAL MANAGEMENT AND

DEVELOPMENT STUDIES

Volume 1, Issue 1 · September 2020 • ISSN 2719-0633 (PRINT) 2719-0641 (ONLINE)

services and the like are considered in order to meet the learning requirements needed. For Domagała-Zyśk (2016), understanding that for the $\mathrm{D} / \mathrm{HH}$, the key difficulties revolve not just in the constrained to non-existent possibility of auditory access to language, but foremost is attaching meaning to the words and expressions used. It is thus suggested by Rosa-Lugo \& Ehren (2018) to revisit the intense literacy strains brought about by laborious standards, curriculum, instruction, and assessment that have serious effects to children and adults with hearing loss learning English as a second spoken language. In most English classes for example, speech, speech-reading and listening are means of communication in native languages only for some $\mathrm{D} / \mathrm{HH}$ people. Distinctive external conditions that would help $\mathrm{D} / \mathrm{HH}$ students learn better such as good visibility, good quality of the speaker's speech and the absence of background distractions should be present in the learning environment. Domagala-Zysk \& Kontra (2016) however argues that these conditions are not easily met, specifically in mainstream classrooms. In the design of suitable teaching methodologies, the consideration of which areas in English language pedagogy should not be the only concern. Rather it should be given more importance as to how educators should approach these pedagogies in ways that would develop the optimal language skills of the $\mathrm{D} / \mathrm{HH}$. As Sollestra (2011) pointed out that there should be a visual modality that matches perfectly the absence of hearing.

\section{Methodology}

The study used quantitative and qualitative designs. The former was used in the testing of the English proficiency level while the latter on the challenges encountered in learning the language. The researcher used total enumeration of the 23 SPED students of the Associate in Computer Technology program under the BS in Information Technology department.

To come up with the data for the English Proficiency level of the respondents, the researcher administered a self-made language test that measure the following language capabilities: grammar, vocabulary, reading comprehension, analysis (cause \& effect, making Inferences) and following directions. To check the validity of the test, the researcher enlisted the expertise of a licensed language instructor as well as the advice of a sign language trainer from a local public high school who handles SPED education in the basic education. To 
INTERNATIONAL JOURNAL OF EDUCATIONAL MANAGEMENT AND

DEVELOPMENT STUDIES

Volume 1, Issue $1 \cdot$ September 2020 - ISSN 2719-0633 (PRINT) 2719-0641 (ONLINE)

gather data regarding the problems they encounter in learning language in their English subjects, a FGD was conducted with the guidance of the two sign language interpreters and in the presence of the sign language trainer to help analyze the data and correspondence of the discussion. The researcher utilized the following data collection tools: Video Recorder (for FGD session), Anecdotal Records (brief notes on the highlights of each observation session or interview) and Basic Information Sheet or Student Records.

The data gathering was conducted on the month of April, during the $2^{\text {nd }}$ semester of School Year 2014-2015 with an actual test given to the students. The first part of the test was the grammar and vocabulary test. Each respondent was handed a written test consisted of 20 items in vocabulary and 20 items in grammar, totaling 40 items. They were given an hour to complete the test.

The second part of the test was for reading comprehension, analysis and following directions. For reading comprehension, a reading material was flashed on a MS PowerPoint presentation and afterwards multiple choice questions were flashed for them to answer. They wrote their answers on a sheet of paper. This was followed by another written exam with two parts: determining cause and effect and making inferences from a short story. A matching type test was given to the respondents where they matched the causes enumerated in column A to the effects in column B. Answers were again written in their answer sheets. For the making inferences part, the researcher read a short story to the respondents while an interpreter signs to the students. The story was also flashed on screen. When the story reached the near end, the researcher asked the respondents what they think happened in the end. They again wrote their answers in their answer sheets. Finally for following directions, the researcher asked the respondents to follow the direction flashed on screen. They were asked to read carefully each of the 10 following direction items before they wrote/did what was asked.

The researcher also conducted a FGD to gather data regarding the problems encountered by the SPED students in their English classes. The discussion was guided by the two (2) SPED interpreters. A set of questions were asked to the students and the group discussed the answers with the help of the interpreters. A sign language trainer was present to interpret and analyze the discussion. The FGD focused on four different key points: Teacher 
INTERNATIONAL JOURNAL OF EDUCATIONAL MANAGEMENT AND

DEVELOPMENT STUDIES

Volume 1, Issue 1 - September 2020 • ISSN 2719-0633 (PRINT) 2719-0641 (ONLINE)

-Deaf student relationship, Teacher knowledge on "how deaf students think and learn", Involvement of parents / family and Teacher-learning strategies intervention.

The results from the English proficiency test in grammar and vocabulary were tallied and analyzed through frequency and percentage. After determining the mean scores, the frequencies were also derived to come up with the number of respondents who fell under the specific set of scores correlated with value interpretation. The researcher based the value interpretations from the rating scale utilized by the college in the computation of student grades. Based on the said scale the researcher set the following value interpretation for the results of the English Proficiency tests used in the study:

$\begin{array}{llll}\text { Score }(\mathbf{5} \text { items }) & \mathbf{( 1 0} \text { items }) & \mathbf{( 2 0} \text { items }) & \text { Value Interpretation } \\ 1-1.99 & 1-2.99 & 11 \& \text { below } & \text { Needs Improvement } \\ 2-2.99 & 3-4.99 & 12-14 & \text { Fair } \\ 3-3.99 & 5-6.99 & 15-16 & \text { Good } \\ 4-4.99 & 7-8.99 & 17-18 & \text { Very Good } \\ 5 & 9-10 & 19-20 & \text { Excellent }\end{array}$

Meanwhile, data from the focus group discussion were analyzed using Conversation Analysis. The researcher focused on the five features identified as being regular parts of conversation within the framework of CA- openings, turn taking, adjacency pairs, repairs, and closings. Said features were outlined in the milieu of conversations that occur between the researcher, the deaf respondents and the interpreter. A brief description of each feature was given within the analysis.

To aid the researcher in analyzing both the context and the prosodic or non-verbal cues in the discussion, the discourse was transcribed using selected key transcription symbols to illustrate the prosodic and timing cues that occurred in the discussion. 
INTERNATIONAL JOURNAL OF EDUCATIONAL MANAGEMENT AND

DEVELOPMENT STUDIES

Volume 1, Issue 1 • September 2020 • ISSN 2719-0633 (PRINT) 2719-0641 (ONLINE)

\begin{tabular}{|c|c|c|c|}
\hline Item & Symbol & Definition & $\begin{array}{l}\text { Transcription } \\
\text { Sample }\end{array}$ \\
\hline Held segment & $:$ & $\begin{array}{l}\text { A colon indicates that the individual has held } \\
\text { or "stretched" a sign. The more colons, the } \\
\text { longer the hold. }\end{array}$ & Yes:: \\
\hline Pause & (.) & $\begin{array}{l}\text { A dot enclosed in parentheses indicates a } \\
\text { pause in the conversation of less than two- } \\
\text { tenths of a second. }\end{array}$ & Example (.) \\
\hline Emphasis & -------- & $\begin{array}{l}\text { Underlining indicates an animated or } \\
\text { emphatic segment }\end{array}$ & Must \\
\hline Latching & $=$ & $\begin{array}{l}\text { An equal sign indicates latching between } \\
\text { utterances in the conversation. }\end{array}$ & $\begin{array}{l}\text { Ask questions? = } \\
=\text { yes... }\end{array}$ \\
\hline $\begin{array}{l}\text { Overlapping } \\
\text { talk }\end{array}$ & [ ] & $\begin{array}{l}\text { Brackets indicate overlapping talk between } \\
\text { the individuals. }\end{array}$ & $\begin{array}{l}\text { [deep words] } \\
\text { [having difficulty } \\
\text { with } \\
\text { understanding...] }\end{array}$ \\
\hline $\begin{array}{l}\text { Non-verbal } \\
\text { activity }\end{array}$ & $(())$ & $\begin{array}{l}\text { Double parentheses indicate prosodic or } \\
\text { nonverbal activity. }\end{array}$ & (( nodding)) \\
\hline
\end{tabular}

Using the symbols in transcribing the discussion, the researcher was able to analyze not just the context of the conversations but also the underlying explanations of the thoughts and emotions of the respondents as they answered each inquiry. Through the help of the invited sign language trainer, a further interpretation and evaluation of the process was provided to determine if the purpose of the discussion was achieved.

\section{Results and Discussion}

\subsection{English Language Proficiency Profile}

Table 1 shows the frequency count of the test scores obtained by the students in the English Language proficiency tests. 
INTERNATIONAL JOURNAL OF EDUCATIONAL MANAGEMENT AND

DEVELOPMENT STUDIES

Volume 1, Issue 1 · September 2020 • ISSN 2719-0633 (PRINT) 2719-0641 (ONLINE)

\section{Table 1}

Results of the English Language Proficiency Tests and their Interpretation

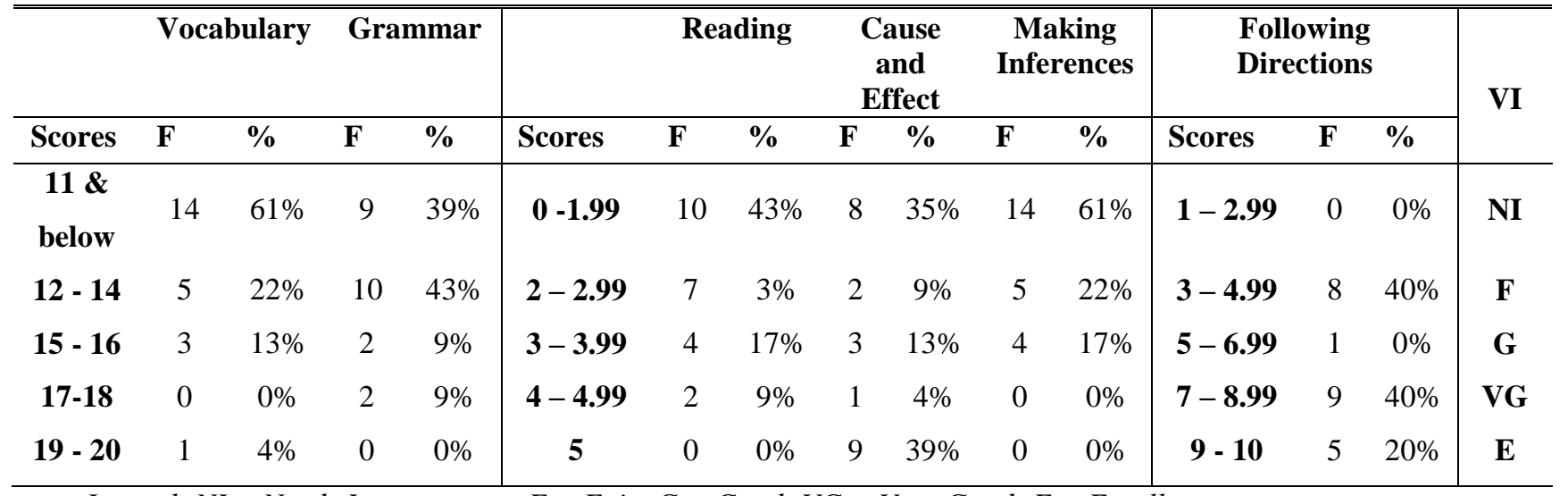

Legend: $N I=$ Needs Improvement $; F=$ Fair $; G=$ Good $; V G=$ Very Good $;$ E = Excellent

As to the vocabulary test, 14 respondents (61\%) fell below the mean score, corresponding to a value interpretation of Needs Improvement. There were 8 respondents who got scores above the mean and got value interpretations of Fair and Good. Meanwhile, one respondent obtained the highest score in the test, 19 out of the 20-item vocabulary test, interpreted as Excellent. Considering that most of the materials chosen for the test were below college level English, the result still shows most of the respondents display below average skills with poor grasp of English words.

Based on the tallied scores for the grammar test, 9 out of the 23 respondents scored below the mean and got a value interpretation of Needs Improvement. Whereas there were two respondents who displayed above average grasp of the English grammar garnering scores 17 - 18 with a value interpretation of Very Good. Compared to the vocabulary test, there was a significant improvement in the results acquired by the respondents in the grammar test.

The results of the reading comprehension test show that majority of the respondents, specifically $43 \%$, fell below the mean score and got a value interpretation of Needs Improvement. About 11 respondents showed average levels of reading comprehension and got scores above the mean, with a Fair and Good value interpretation. Finally, there were only 2 respondents who obtained a score of 4 out of the 5-item reading comprehension test equivalent to Very Good. It is clear from the results, that most of the respondents exhibit very 
INTERNATIONAL JOURNAL OF EDUCATIONAL MANAGEMENT AND

DEVELOPMENT STUDIES

Volume 1, Issue 1 · September 2020 • ISSN 2719-0633 (PRINT) 2719-0641 (ONLINE)

low comprehension skills, as the majority of them did not answer more than half of the questions correctly.

In the cause and effect test, 10 respondents fell below the mean score; 5 of these respondents, who got a value interpretation of Needs Improvement, got a score of 0 . Meanwhile, $39 \%$ of the respondents got a perfect score of 5, with a value interpretation of Excellent.

In the making inferences test, 14 or $61 \%$ of the respondents fell below the mean, getting a value interpretation of Needs Improvement. This indicates that majority of them, have very low skills in making inferences from stories. $22 \%$ (5 respondents) got scores of 2, with a value interpretation of Fair and were at least attempted to draw conclusions although there were inaccuracies in details and unsubstantiated predictions. Only4 respondents who got scores of 3 were able to draw out somewhat accurate conclusions derived from the story. However, it still contained inaccurate details and they were not able to write their predictions in grammatically correct sentences. These respondents got a value interpretation of Very Good.

Lastly, the following directions test scores show that the respondents showed the highest proficiency, as there were 15 respondents whose scores were above the mean. Only about 35\% (or 8 respondents) fell below the mean score. The results of the Following Directions test indicate that compared to the other areas of the test, this is where the respondents display a relatively average capacity in understanding and following instructions.

Table 2 shows the summary of mean scores of all the five areas tested with their corresponding value interpretations. Overall results show that only the 'Following Directions' test got an impressive 6.13 mean score interpreted as Good. The areas Grammar and Cause \& Effect Analysis both with 'Fair' equivalence of their mean scores of 11.91 and 2.82 , respectively. Three of the six items fell on the lowest scale 'Needs Improvement which include vocabulary (10.86 mean score), reading comprehension (1.6 mean score) and making inferences (1.56 mean score). 
INTERNATIONAL JOURNAL OF EDUCATIONAL MANAGEMENT AND

DEVELOPMENT STUDIES

Volume 1, Issue 1 • September 2020 • ISSN 2719-0633 (PRINT) 2719-0641 (ONLINE)

Table 2

Summary of mean scores and mean level performance

\begin{tabular}{ccl}
\hline \hline Areas of English Proficiency & Mean Score & Value Interpretation \\
\hline 1. Vocabulary & 10.86 & Needs Improvement \\
2. Grammar & 11.91 & Fair \\
3. Reading Comprehension & 1.6 & Needs Improvement \\
4. Analysis (Cause \& Effect) & 2.82 & Fair \\
5. Analysis (Making Inferences) & 1.56 & Needs Improvement \\
6. Following Directions & 6.13 & Good \\
\hline
\end{tabular}

The three areas with lowest proficiency seemingly attributed to their limited grasp for English words. This may contribute to the fact that it seems difficult for majority of them to comprehend reading materials. That in turn also shows why they also have below average skills in predicting outcomes or drawing out conclusions from a story. Their results likewise show a relatively higher proficiency in grammar as compared to their vocabulary skills. While they show below average skills in making predictions, as far as analysis is concerned, they are more able to evaluate cause and effect relationships. The study also showed that their highest skill appears to be in following directions as this is where they obtained the highest scores in the whole test.

The results of the English Proficiency tests indicate that the respondents acquired low proficiency scores more particularly apparent in the Vocabulary, Reading Comprehension and Making Inferences part. Although they did show slightly higher proficiencies in the areas of Grammar, Cause and Effect and Following Directions, the results do not show a proficiency in English that matches that of a college student. However, it must be considered that the respondents have sensorial disabilities that inhibit them to acquire language skills like that of a hearing student. The results will consequently render an English Language Proficiency Profile indicating their strengths and weaknesses in the English language.

Beyond what the profile reveals, there should also be an understanding on the reason why they have delays in language development that is subsequently reflected in their performance in the tests. It is interesting to note how the respondents reacted while taking the 
INTERNATIONAL JOURNAL OF EDUCATIONAL MANAGEMENT AND

DEVELOPMENT STUDIES

Volume 1, Issue 1 · September 2020 • ISSN 2719-0633 (PRINT) 2719-0641 (ONLINE)

tests. Even with aid of the two interpreters in explaining the test questions, the researcher observed that they have difficulty grasping some concepts of words unless the interpreters gave them visual examples. This observation is substantiated by Sollestra (2011) that deaf people are 'eye' people where sign language is considered a 'visual-gestural language'.

\subsection{Problems Encountered In Learning English}

This part focused on the five features of regular parts of a conversation in the framework of CA. An example of the transcription for each feature is discussed including a brief description. The sample utterances are numbered in the left part to indicate the sequencing of the turn taking and the abbreviations $\mathbf{R}$, refers to the researcher, $I 1$ refers to the male interpreter, $I 2$ refers to the female interpreter and RES refers to "respondents".

\section{A. Opening}

This is the part where the conversation or the discussion starts. In the CA framework, there are various core sequences in opening a conversation. The sequence used in this particular FGD is called a "summons answer", where an individual poses a question or offers a leading statement to begin the conversation. The FGD opened with the researcher explaining what the discussion is about and how it will transpire. It should be noted that before the actual filming the researcher explained to the two interpreters and the sign language trainer how the researcher will conduct the discussion. The transcription provided below occurred after the filming began.

O1 R: So (.) this morning (.) we will discuss some possible problems that you may encounter in learning the English language, in your English classes.

So I'm going to ask you questions regarding this. Anybody can answer if you want. Raise you hand(( raises hand to show to respondents)) if you want to answer ok ::

02 I1: (( signs the instructions to respondents))

03 R: ((researcher looks at interpreter to see if she can begin asking questions)) 
In the discussion, the researcher opened by explaining to the respondents what the discussion is about and how the discussion will be conducted. There were already a few pauses from the opening of the discussion which indicates that the researcher is being careful in trying to start the conversation with the respondents. The researcher deliberately chose to give a brief opening so that the respondents can easily comprehend. It was also evident that there were parts stressed, for instance emphasizing that the discussion is focused on their English class, and emphasizing instructions through actions. The researcher also looked at the interpreter before starting the questions as verbal cues would come from the interpreter.

\section{B. Turn Takings}

One of the more important features of CA is how turn takings unfold in a discussion. Turn taking simply put, is the completion of an utterance of one individual involved in the discussion to give way to another. A "turn" is signaled either by a simple word or signal, a long sentence or a series of utterances that lasts for several minutes or prosodic cues. There were many points of turn taking in the discussion. Instead of a simple 2-way conversation however, the turn takings involved the researcher, the interpreter (either of the two interpreters present) and the respondent. The researcher addressed the question to the respondent, the interpreter asked the question through sign language to the respondent, and the interpreter relayed the answer to the researcher.

01 R: So:: do you think you are able to understand you work better in English Sa mga English assignments nyo pag (.) yung parents or yung family ang nagtuturo(.) mas naiintindihan nyo ba siya? (.) or :: [ay yundaw] ((points at one respondent))

02 I1: [yes, yes] ((signs getting answers from respondents))

03 R: yes? Yes? Ahh:: bakit? Bakit mas naiintindihan pagka (.) magulang or family angnageexplainsa English? :: ((waiting for reply)) 
INTERNATIONAL JOURNAL OF EDUCATIONAL MANAGEMENT AND

DEVELOPMENT STUDIES

Volume 1, Issue $1 \cdot$ September 2020 - ISSN 2719-0633 (PRINT) 2719-0641 (ONLINE)

04 I1: ((interprets question through sign))same meaning, Ahh :: ((nods)) saenglish, parangnatututunan : ((trying to understand sign reply of respondents))

I1: with my parents...as the mother...or the mother signs very well. [I can understand it]

R: [ah...in her case] her mother signs [very well]

\section{I1: [oo] ((nods and signs to respondent)) maalamang mother mag sign ((nod))}

It was quite expected that there were many non-verbal activities or prosodic cues when communicating with the deaf. Aside from the interpretation relayed by the interpreter regarding their replies to the question, the only way the researcher can understand their thoughts was through their facial expressions while they are signing. Although it was noticeable that turn taking took place more between the researcher and the interpreter, there were cues that the researcher took from the respondents themselves. This is why the researcher looked at the respondents intently while asking the questions or waiting for their answers. There were also quite a number of overlapped utterances between the researcher and the interpreter, indicating that one individual did not wait for the other to finish. It would be evident from the transcription that it was the researcher who often expresses her utterances hastily.

\section{Adjacency Pairs}

Adjacency pairs are pairs of utterances that are ordered; that is, there is a recognizable difference between the first part and the second part of the pair. Examples of this are question and answers, greetings and return greetings and invitations and acceptance / declinations. There were certain but very seldom points in the discussion that featured adjacency pairs, mostly because the discussion involved many participants. But there were points when the conversation was between the researcher and one of the interpreters.

01 R: Napapansin nyo ba kung (.) yung activities or yung lessons ay (.) ((gestures with hands)) naadjust? ((turns to I2 and waits for reply))

Uhhm...english, English (.) ke Mam Alice it is adjusted...Oo? (.) 
INTERNATIONAL JOURNAL OF EDUCATIONAL MANAGEMENT AND

DEVELOPMENT STUDIES

Volume 1, Issue $1 \cdot$ September 2020 - ISSN 2719-0633 (PRINT) 2719-0641 (ONLINE)

Meron? Example, example, paano example?

02 I2: Mga play nila....

03 R: Ano pong difference pagsa SPED?

04 I2: Yung kanila (.) yung based on (.) yung naranasan na nila sa lesson para madali na maka cope.

05 R: Uhhhmm??:::

In this transcription it appeared that the long pause at the end of their conversation indicated that the researcher was quite confused with the answer of the interpreter. The reply did not clearly explain what the researcher was asking the interpreter. The tone at the end implied that clearly the researcher still has questions.

\section{Repairs}

Repairs refer to how individuals in conversation deal with challenges in speaking, hearing, or understanding. Repair segments are classified by who initiates repair, by who resolves the problem, and how the repair unfolds within a turn or a sequence of turns. In the discussion, there was a point in the beginning, where the researcher felt frustrated that the respondents did not seem to be reacting to the questions. The researcher felt that the questions were not being clearly relayed. In an attempt to repair the situation, the researcher kept on repeating the questions.

01 R: Ano, nag aapproach ba kayo sa teacher? :.:: do you approach your teachers in English pag ahh (.) pag me gusting linawin sa assignments (.) or sa subject ::: anong reason kung bakit no? :::

02 I1: ((signs while asking and explaining the question))

03 R: Ano daw po..... Kanina ang daming nag raise ng hand ((raises hand to encourage reaction from respondents))

04 I1: (raises hand to ask respondents))

05 R: You.... ano daw? ((looking at I1 and a respondent talk in sign language))

06 I2: sinong may sabing yes? Taas ang kamay ((signs while giving instructions)) Yes?? ((asking respondent though sign)) Ano....oh taas ang kamay! 
INTERNATIONAL JOURNAL OF EDUCATIONAL MANAGEMENT AND

DEVELOPMENT STUDIES

Volume 1, Issue $1 \cdot$ September 2020 - ISSN 2719-0633 (PRINT) 2719-0641 (ONLINE)

07 R: ((trying to understand sign conversation of II and a respondent)) Ano daw po Sir?

08 I1: nagtatanong din daw siya::: ((trying to understand respondent)) pero :::

09 R: pero:::

10 I1: deep ang words....

11 R: [Hard]

12 I1: [hard] and vocabulary....

13 I2: [deep and English words]

It was apparent in the transcription that there was a point in the discourse where the researcher felt frustrated that the respondents were not responding or reacting to the questions. The researcher kept on asking the questions trying to make the idea clearer for the respondents. In an attempt to repair the confusion, one of the interpreters tried a more aggressive approach in making the respondents raise their hand or offer a reaction, while the other interpreter continued clarifying the questions to the respondents and tried to understand the reply.

\section{E. Closings}

This is the part of the conversation where one individual brings the discussion to an end. It requires one speaker to directly or indirectly end the conversation. In the closing part of the discussion, the researcher gave a more detailed explanation why the study was conducted, the purpose of the study and what can be a possible outcome in the future. The closing was a bit lengthy so only an excerpt was included here as an example.

01 R: So ::: alright:: So(.) yun lang po...((laughing))...Ang purpose po nung study (.) gusto ko rin lang po malaman ng mga kids (.) gusto kong malaman yung level ng proficiency nyo sa English (.) alam naman natin na medyo nahihirapan kayo sa language (.) mabuti ngayon (.) it's good that the teachers in English are able to adjust (.) the lessons...

.....so that's solely for your English proficiency (.) we want to see ano talaga level ng ating deaf learners. Para maibigay naman namin yung best service eventually sa laha ng deaf na mag aaral. Para pag graduate nyo (.) ay (.) 
INTERNATIONAL JOURNAL OF EDUCATIONAL MANAGEMENT AND

DEVELOPMENT STUDIES

Volume 1, Issue 1 · September 2020 • ISSN 2719-0633 (PRINT) 2719-0641 (ONLINE)

yung level ng communication, yung language, language acquisition, level ng communication...hopefully we will see an improvement though ::: that specialized program that we will offer para sa language::: ((smiles to the respondents))

\section{Ok::: ((laughs)) so thank you very much for taking part in my study...}

\section{I1: ((signs to the respondents while researcher talks))}

In the closing part of the discussion, the researcher did all the talking while the interpreter signs. As expected, the respondent's attention was focused on the interpreter while the researcher gives the closing. The researcher kept saying the words "ok" and "alright" as a signal that the discussion has reached its end point.

The videotaped session of the FGD was also viewed by the sign language trainer for the necessary analysis. These were some of the points stressed in the analysis:

1. The videographer was not able to focus more on the respondents. As a result it did not show much of the respondents' actual reactions specially their non-verbal and prosodic cues that would have helped in better analyzing the respondents' reactions.

2. It takes time for a deaf student to process any message being relayed to them through sign. This may explain why the respondents do not get to react or reply immediately after the researcher asked the question.

3. The questions were asked too fast and too frequent that the respondents got confused. As a result they do not get to react or reply immediately.

4. It was noticed that interpreters were also taking some time interpreting the questions. It seemed that the researcher was not able to show the questions to the interpreters in advance. It was advised that questions should be discussed or at least shown to the interpreters so they would already be familiar before they interpret it to the respondents.

5. There was "reverse interpretation", where instead of signing a particular message or question to the deaf, interpreters construct the message into an acceptable spoken message. There are certain parts of speech that have no sign language equivalent. 
INTERNATIONAL JOURNAL OF EDUCATIONAL MANAGEMENT AND

DEVELOPMENT STUDIES

Volume 1, Issue 1 · September 2020 • ISSN 2719-0633 (PRINT) 2719-0641 (ONLINE)

Based on the proceedings of the FGD, the following concerns were identified under the four key areas focused in their learning environment:

\section{A. Teacher-Deaf student relationship}

Some of the respondents expressed their uncertainty in approaching their English teacher because they did not understand well the lectures and do not know exactly what to ask. According to them the words were too "deep" or too "hard" for them to understand. Although English teachers have adjusted lessons and activities in their classes to make it easier for the deaf students to cope, according to the deaf students in their third year level, this was not the case before. Their English teachers back then give the same activities and employ the same teaching approach to both the hearing and the deaf in the class.

\section{B. Teacher knowledge on "how deaf students think and learn"}

The same concern was raised by the same deaf respondents in this area. Because at the time these students were taking their English classes, the SPED program was still new, the teachers were still not oriented on how to handle deaf students. It was quite remarkable that English teachers currently give consideration and exert efforts in trying to adjust the subject for the deaf students.

\section{Involvement of parents / family}

Majority of the respondents expressed that they get enough support from their family, particularly their parents. In fact, they even implied that they find it easier to understand their assignments in English when their family members help them. There was not much problem in this area, except for a minority of the respondents who do not have parents around.

\section{Teacher-learning strategies or intervention}

For the nine students in their third year level of study, they expressed that it was difficult for them to cope in their English classes before due to the lack of strategies employed by English teachers to help them cope in their subject. The activities and lessons were centered on materials that were designed for hearing students. 


\section{Conclusion}

This case study made an in-depth inquiry of the Special Education (SPED) students in one of the community colleges in Quezon Province, Philippines. Profiling their English language proficiency showed that their proficiency is not of college level. The areas in which they showed the lowest scores in the tests which are vocabulary, reading comprehension and making inferences clearly point to the expected language limitations of someone with sensorial disabilities. Meanwhile, they expressed difficulty in coping with the learning requirements of their language classes which are designed for hearing students. As the respondents are considered a minority in the college, the learning approaches used by the instructors are designed for the majority of the student population which are the hearing students.

The teachers need to understand the nature of their students. In this case, the language of the deaf is totally different with that of the hearing to begin with. No matter how they try to make them proficient in the English language, efforts will be futile unless they use an approach applicable to the D/HH's own system of English language. For this, the college has a much bigger responsibility to provide support services for the students with special needs. These include an appropriate curriculum, teachers training program, differentiated learning materials and an inclusive class environment. The road to the English language proficiency of the SPED students is rough but there are ways and means the college can put in place to achieve the goal.

The results of the current study, given its limited scope and sample size, opened various related aspects of special education. The exclusion of the English language teachers for a triangulation approach might have impact on the analysis. Thus, the researcher recommends further studies that focus on teaching approaches and methodologies and its effect on the language proficiency of the D/HH students. Further, demographic profile of the students may be considered as factors for the language proficiency. 
INTERNATIONAL JOURNAL OF EDUCATIONAL MANAGEMENT AND

DEVELOPMENT STUDIES

Volume 1, Issue $1 \cdot$ September 2020 ・ ISSN 2719-0633 (PRINT) 2719-0641 (ONLINE)

\section{References}

Bowers, L., Dostal H., Wolbers, K., and Graham, S. (2018), The Assessment of Written Phrasal Constructs and Grammar of Deaf and Hard of Hearing Students with Varying Expressive Language Abilities, Hindawi Education Research International Volume 2018, Article ID 2139626, pp. 1-10

Bustos, M. P. (2007). Exploring Emergent Literacy Behaviors of Filipino Deaf Children. $\begin{array}{llll}\text { Retrieved January } & 12,3 & \text { from }\end{array}$ http://www.dlsu.edu.ph/research/journals/taper/pdf/200706/bustos.pdf

Campbell, R. et. al., (2007), Sign Language and the Brain: A Review, Journal of Deaf studies and Deaf Education 13:1, 2008, DOI: 10.1093

Chery, K and Gan S. MD, (2020), How the Theory of the Mind Helps Us Understand Others, Psychosocial Psychology, Very Well Mind, Retrieved August 18, 2020 from https://www.verywellmind.com

Chomsky, N. (1965). Aspects of the theory of syntax. Cambridge, MA: MIT Press.

Csizer, K. and Kontra, E. (2020), Foreign Language Learning Characteristics of Deaf and Severely Hard-of-Hearing Students, The Modern Language Journal, 104, 1, (2020), DOI: $10.1111 / \bmod 1.12630$

Domagała-Zyśk, E. (2016). Vocabulary Teaching Strategies In English As A Foreign Language Classes For Deaf And Hard-Of-Hearing Students. In Domagala-Zysk, E. \& Kontra, E.H. (Eds.) English as a Foreign Language for Deaf and Hard-of-Hearing Persons: Challenges and Strategies. UK: Cambridge Scholars Publishing

Domagala-Zysk, E. \& Kontra, E.H. (2016). English as a Foreign Language for Deaf and Hard-of-Hearing Persons: Challenges and Strategies. UK: Cambridge Scholars Publishing

Easterbrooks, S. R., \& Stoner, M. (2006). Using a visual tool to increase adjectives in the written language of students who are deaf or hard of hearing. Communication Disorders Quarterly, 27(2), 95-109. doi:10.1177/15257401060270020701

Fox, A. and Falk, J. (2019), Deaf Children as 'English Learners': The Psycholinguistic Turn in Deaf Education, Education Sciences, June 2019, 9, 133; DOI:10.3390 
INTERNATIONAL JOURNAL OF EDUCATIONAL MANAGEMENT AND

DEVELOPMENT STUDIES

Volume 1, Issue $1 \cdot$ September 2020 ・ ISSN 2719-0633 (PRINT) 2719-0641 (ONLINE)

Hall, M., Hall, W. and Caselli, N. (2019), Deaf children need language, not (just) speech, First Language 2019, Vol. 39, DOI: 10.1177/0142723719834102

Heward, W. L. (2012). Exceptional children: An introduction to special education. Boston: Pearson Educational Inc.

Howerton-Fox, A. \& Falk, J.L. (2019). Deaf Children as 'English Learners': The Psycholinguistic Turn in Deaf Education. Educ. Sci. 2019 2019, 9, 133, pp 1 - 29. DOI:10.3390/educsci9020133

Marschark, M., Shaver, D.M., Nagle, K.M. \& Newman, L. A. (2015). Predicting The Achievement Of Deaf And Hard-Of-Hearing Students From Individual, Household, Communication And Educational Factors. Exceptional Children, vol. 81, no. 3, pp. 350-369, 2015.

Obosu, G.K., Opoku-Asare, N.A. \& Deku, P. (2016), Access to English Language Acquisition in Ghana Schools for the Deaf: Are the Deaf Students Handicapped, Journal of Education and Practice, Vol.7, No.35, 2016, pp. 17-34

Pinker, S. (1994). The Language Instinct: How the Mind Creates Language. Harvard University Press.

Piaget, J. (1936). Origins of intelligence in the child. London: Routledge \& Kegan Paul.

Rosa-Lugo, L. and Ehren, B. (2018), Impact of Escalating Literacy Demands on English Learners With Hearing Loss, Wolters Kluwer Health, Inc, Vol. 38, No. 3, pp. 171193, DOI: 10.1097

Rowh, M. (2006).Write well, go far. Career World, 34(4), 18-21.

Schick, B. (2014) Social Cognition and Theory of the Mind Retrieved January 8, 2014 from http://www.handsandvoices.org/comcon/articles/socCogTheorMind.html

Scott, J.A. \& Dostal, H.M. (2019). Language Development and Deaf/Hard of Hearing Children. (In) Peter V. Paul. The Education of d/Deaf and Hard of Hearing Children Perspectives on Language and Literacy Development. Educ. Sci. 2019, 9, 135, pp 22 - 35. DOI:10.3390/educsci9020135 
INTERNATIONAL JOURNAL OF EDUCATIONAL MANAGEMENT AND

DEVELOPMENT STUDIES

Volume 1, Issue 1 · September 2020 • ISSN 2719-0633 (PRINT) 2719-0641 (ONLINE)

Sollestra, P. (2011). Teaching English for the Deaf from the Eyes of a Hearing Priest. $\begin{array}{llll}\text { Retrieved April 6, } & \text { 6rom }\end{array}$ https://deafphilippines.wordpress.com/2011/11/12/teaching-english-for-the-deaffrom-the-eyes-of-a-hearing-priest/.

Turnbull, A. P., Turnbull III, R., Shank, M., \& Leal, D. (2009). Exceptional lives: Special education in today's schools. Englewood Cliffs, New Jersey: Prentice-Hall Inc. 